Association for Information Systems

AIS Electronic Library (AISeL)

Wirtschaftsinformatik 2021 Proceedings

Track 21: Enterprise Modelling and Information

Systems Development

\title{
Capturing the Dynamics of Business Models: Towards the Integration of System Dynamics and Reference Modeling
}

\author{
Maren Stadtländer \\ Universität Hildesheim \\ Thorsten Schoormann \\ Universität Hildesheim \\ Ralf Knackstedt \\ Universität Hildesheim
}

Follow this and additional works at: https://aisel.aisnet.org/wi2021

Stadtländer, Maren; Schoormann, Thorsten; and Knackstedt, Ralf, "Capturing the Dynamics of Business Models: Towards the Integration of System Dynamics and Reference Modeling" (2021).

Wirtschaftsinformatik 2021 Proceedings. 9.

https://aisel.aisnet.org/wi2021/DEnterpriseModelling21/Track21/9

This material is brought to you by the Wirtschaftsinformatik at AIS Electronic Library (AISeL). It has been accepted for inclusion in Wirtschaftsinformatik 2021 Proceedings by an authorized administrator of AIS Electronic Library (AISeL). For more information, please contact elibrary@aisnet.org. 


\title{
Capturing the Dynamics of Business Models: Towards the Integration of System Dynamics and Reference Modeling
}

\author{
Maren Stadtländer ${ }^{1}$, Thorsten Schoormann ${ }^{1}$, and Ralf Knackstedt ${ }^{1}$ \\ ${ }^{1}$ University of Hildesheim, Information Systems, Hildesheim, Germany \\ \{maren.stadtlaender,thorsten.schoormann,ralf.knackstedt\}@ uni-hildesheim.de
}

\begin{abstract}
In face of the complexities of business models as well as their dynamic and uncertain environments, business model designers increasingly rely on a systemic view, for example by applying System Dynamics. Despite acceptance in research and practice, this approach comes however with several drawbacks such as high complexity of model construction and the models themselves. To overcome these challenges, we examine the potential of integrating reference modeling and System Dynamics. In this study, we describe the expected benefits and requirements of reference modeling for business models, give a preliminary overview of suitable reference model components, and outline promising directions of our ongoing and future research.
\end{abstract}

Keywords: Business Modeling, System Dynamics, Reference Models.

\section{Introduction and Problem Awareness}

With the rising complexity, dynamics, and interconnectedness of today's businesses and the innovation of existing and introduction of entirely new business models, research increasingly understands a business model as "a complex system of interrelated subcomponents [...] interacting with heterogenous internal and external influences leading to the evolution of its components and the system itself" (p. 8) [1], with the notion that "business models themselves are never static" (p.3) [2]. This requires firms to view their business model through a systemic lens across the entire lifecycle in order to prevent undesired consequences of their design choices or, in the worst case, the implementation of non-viable business ventures.

Visualization has been considered a promising approach to guide the development and assessment of business models [3]. Thus far, business model modeling languages (e.g., the Business Model Canvas (BMC) [4]) often take a static view of the components implemented to create and deliver value [2]. However, as the components of a business model such as its value proposition and revenue model are highly interdependent [5], business model development can benefit from considering these interrelations. In this line, the approach of System Dynamics (SD) [6] has started to be recognized with acceptance from scholars (e.g., [7, 8]) and practitioners (e.g., [9]) alike. Generally, SD offers notations for depicting the causal relations in a system as well as diagrams

16th International Conference on Wirtschaftsinformatik,

March 2021, Essen, Germany 
examining its state with the goal of emulating a system's past behavior and identifying the root cause(s) for a behavior under examination. Studies using SD in the context of business models include modeling sustainability-oriented business models [10], case studies on benefits of SD for business model innovation [7, 9], and case studies adapting the BMC to create a causal loop diagram [11]. Also, SD is researched for assessing a business model's viability [12] and experimenting with business model alternatives [13]. However, even though SD is a useful tool for (re-)designing and assessing business models, the approach comes with several shortcomings: (a) business models captured with SD are often overwhelmingly large and complex [7, 9, 14], especially since (b) many users (e.g., practitioners or managers) lack experience with them, leading to low-quality models and dependence on external modeling expertise $[9,11$, 15]. SD is (c) not easy to learn and apply [15], particularly whenever the stakeholders involved wrongly expect a quick and simple modeling experience [14], or when they thus far have embraced a static, linear mindset towards business models [11]. Lastly, (d) while it is generally desirable to include a diverse set of stakeholders at the business model design stage, this diversity of views has been observed to lead to a "least common denominator consensus" (p. 397), in which stakeholders resort to oversimplifying, modeling linear causal links between elements, or applying "conventional business model logic" (p. 400) [7]. This is detrimental because SD specifically aims to examine non-linear relationships between elements of a system.

Against this backdrop, this short paper reports on the first steps of an overarching Design Science Research (DSR; [16, 17]) project in which we explore how the reuse of model components or entire models can bridge these shortcomings and support business model designers. While approaches for model reuse exist in different fields such as software engineering (cf. [18] for an overview), we specifically suggest to build upon reference modeling (RM) (e.g., [19-22]). We find RM promising as this approach is not only established in Information Systems research and practice (for an overview see [23]; more recent studies apply RM to, e.g., business process management [24, 25], or data modeling [26] and management [27]) but has also been applied in the context of business models (e.g., [28-31]) and dynamic modeling (e.g., [32-34]) before. As overarching goal of our research, we therefore pose the following question: How to make use of reference modeling to overcome the challenges when applying SD in business model development? Overall, we bring together three different streams: business model development, System Dynamics, and reference modeling. In this paper, we present our first steps towards developing an artifact (a reference model) to respond to our research question by giving an awareness of problems arising through the use of SD for business model development (Section 1) and making a suggestion for addressing these challenges through reference modeling (Section 2). Next, we provide an overview of studies using SD for business model development. Thereby, we tentatively identify a starting point for reference model development in the form of potentially reusable model components, and thereby demonstrate the feasibility of reference modeling in this domain, while pointing out gaps requiring further examination (Section 3). Finally, we give an outlook next steps regarding the research question (Section 4). 


\section{Reference Modeling for System Dynamics-based Business Model Development}

Reference models can be defined as reusable "generic conceptual models that formalize state-of-the-art or best practice knowledge of a certain domain" (p. 2) [22], and reference modeling as the act of constructing and applying such models [19]. Through reference modeling, benefits such as time and cost reduction during model construction and increased model quality are expected to arise [21] - thus, promising avenues to address the aforementioned challenges of SD in terms of (re-)designing business models. Additionally, we expect reference models to provide a valuable basis for less experienced modelers because a pre-defined structure allows them to explore the complex interdependencies of a business model without the pitfall of (wrongly) assuming linear causal relations, and supports including only relevant variables for decreased model complexity. Research has already begun to explore the use of generic SD models in the context of business design and assessment (e.g., [11, 13, 35-37]). However, the majority has focused on describing cases in which a general model was used as a basis for constructing a specific one (e.g., [38], building upon the BMC), with limited elaboration on the benefits of model reuse (e.g., best practice knowledge) in the modeling process itself or how to derive such generic models. Hereby, the potential of reference modeling in supporting SD-driven business model design remains untapped. Moreover, we lack specific requirements for how a reference model and its corresponding reference model components (i.e., partial models or single elements that are then, for example, aggregated) should be designed and applied. Therefore, we base our suggestion particularly on requirements from reference modeling literature. For designing a purposeful solution in the form of a reference model for SD-based business model development, the following requirements need to be considered.

First, different criteria concerning reference model quality like generality, flexibility, completeness, usability, and understandability are stressed in literature [39]. In context of business model design this implies, for example, that a reference model should be generic enough to apply to different projects while remaining helpful to an individual designer, which also requires considering the tradeoff between generality and specificity [21]. Also, the reference model should contain all necessary business model components to be considered complete. Thus, as a first requirement, a reference model for $S D$-based business model design must adhere to general RM quality criteria (RQ1).

Second, business model designers require support when applying the reference model to their project. Literature suggests, for example, methodical support, the use of model (component) repositories, or automated approaches for adaptation [21]. Hence, support for business model designers in applying the reference model is needed (RQ2).

Third, RM research describes language-based requirements such as: adaptability of the language [40]; enabling placeholders, integrating interfaces or connectors for aggregating model components, and providing generic, adaptable elements [41]; highlighting components in need of adaptation [21]. While some, such as modules for aggregating several models, are already available for SD [42], others may require extending the SD notation or integrating further languages. Therefore, our solution should make use of existing SD constructs and extend them where necessary (RQ3). 


\section{Reference Model Components in Related Literature}

To identify a status quo and potential base for deriving reference model components, we conducted a preliminary literature survey on articles applying SD to business models. Following [43], we searched AISeL, Wiley Online Library, Science Direct, ACM, and JSTOR for "system dynamics" and terms related to business models and business model frameworks (e.g., "business model", "resources", "service provision"; 8 relevant studies). We extended this literature base through a forward and backward search [43] starting from two recent papers [7, 11], which yielded another 6 relevant articles, and analyzed the SD models using the framework by [44].

Table 1 gives an overview of the results, with each line describing an SD model and indicating the components of a business model included. We list both generic models (i.e., providing generalized SD elements) and non-generic models (i.e., capturing a specific case; marked with an asterisk). Studies containing a generic and a non-generic SD model mapping the same business model components $[11,36]$ have been grouped in the table. Through our analysis, we were able to examine for which business model components generic or non-generic models or model elements already exist that may serve as a basis for the subsequent development of reference model components.

Table 1. Potential reference model components per business model component [44] (• model contains element for business model component, * generic model)

\begin{tabular}{|c|c|c|c|c|c|c|c|c|c|}
\hline Source & 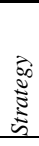 & 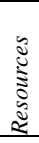 & $\begin{array}{l}\frac{\pi}{0} \\
\text { हे } \\
z \\
\end{array}$ & 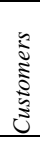 & 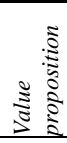 & 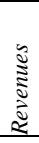 & 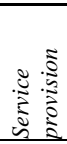 & 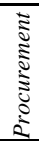 & 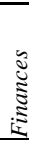 \\
\hline$[11] /[11]^{*}$ & -- & $\bullet$ & • & $\bullet$ & $\bullet$ & $\bullet$ & • & -- & $\bullet$ \\
\hline$[13]^{*}$ & -- & • & • & - & $\bullet$ & • & • & -- & $\bullet$ \\
\hline$[35]^{*}$ & -- & $\bullet$ & • & $\bullet$ & $\bullet$ & • & • & -- & $\bullet$ \\
\hline$[36] /[36]^{*}$ & -- & • & • & • & $\bullet$ & $\bullet$ & $\bullet$ & -- & • \\
\hline [37] & -- & -- & -- & • & • & • & $\bullet$ & -- & • \\
\hline$[38]^{*}$ & -- & -- & -- & -- & -- & $\bullet$ & -- & -- & $\bullet$ \\
\hline [45] & -- & -- & -- & -- & -- & -- & -- & -- & $\bullet$ \\
\hline [46] & $\bullet$ & $\bullet$ & -- & -- & -- & $\bullet$ & • & -- & $\bullet$ \\
\hline [47] & -- & -- & -- & -- & $\bullet$ & -- & -- & -- & -- \\
\hline$[48]^{*}$ & $\bullet$ & $\bullet$ & -- & $\bullet$ & -- & $\bullet$ & $\bullet$ & -- & $\bullet$ \\
\hline [49] & -- & $\bullet$ & $\bullet$ & $\bullet$ & $\bullet$ & $\bullet$ & & -- & $\bullet$ \\
\hline [50] & -- & -- & - & -- & -- & • & • & -- & • \\
\hline [51] & -- & $\bullet$ & -- & -- & -- & • & -- & -- & $\bullet$ \\
\hline$[52]^{*}$ & -- & $\bullet$ & • & - & $\bullet$ & $\bullet$ & -- & • & $\bullet$ \\
\hline
\end{tabular}

The following five main observations emerge: First, those models describing the most components often use the BMC as a generic blueprint and for structuring the variables (e.g., [11, 13, 35, 37]). Second, monetary aspects (revenues and finances), which are relevant economic factors and easily quantified, are most represented across the models (e.g., maintenance spending [49], total salary [35]). Third, the strategy behind a 
company's business model (e.g., outsourcing policy [46]) is underrepresented in our sample. Fourth, some of the generic models provide examples of more specific variables to use in place of the generic ones (e.g., "Resource_l eg Raw materials" [36]). Finally, in some cases, the SD elements mapping one business model component are not tightly interconnected, but instead individual elements for the specific component are dispersed across the entire model (e.g., [49]), which may hinder easy reuse.

\section{$4 \quad$ Research-in-Progress and Outlook}

In this paper, we have motivated reference modeling as a promising approach for overcoming challenges of using SD in business model development and assessment such as a high model complexity and difficulty of the construction process. Furthermore, we have derived an initial set of requirements, and given an overview of existing SD models providing a basis for designing reference model components. In line with the DSR methodology, several steps are necessary for developing and evaluating our artifact. First, most often generic components form the base for applying reference modeling [53]. These may be entirely generic or dedicated to, for example, a specific industry. Hence, we need to elicit generic components from existing research and practice. One of the advantages of SD is the opportunity to create models precisely capturing an individual system. Standardized reference model components can lower the cost (time, money) of modeling, while potentially limiting a precise match between the model and the real system. Therefore, in line with the requirements described in Section 2, we need to identify a suitable level of standardization for the reference model, considering model fit and modeling cost. Second, SD modeling and simulation can be applied during business model design (e.g., [35]), but also for assessment after its implementation (e.g., [49]). Therefore, it is necessary to examine how SD modeling integrates into the business model lifecycle and adapt existing business model development methodologies or propose new ones. Third, various researchers highlight the benefit of applying software tools for developing business models (e.g., [2, 54-56]). However, there is in general a lack of SD-driven tools to support developing business models with a systemic mindset [13], wherefore it is necessary to examine requirements of tools for SD-driven business model development allowing for reference modeling support and how these may be instantiated as a software prototype. Finally, our reference model must provide a satisfactory solution to the identified shortcomings, and ideally should be compared to other available reuse approaches. To ensure quality of the solution, guidelines for evaluating reference models (cf. [19]) should be considered.

Ultimately, we hope to extend existing research on model reuse in using SD for business model design through a reference model and its application in order to empower business model designers to capture the dynamics of business models and their uncertain environment.

Acknowledgement. This work was partially funded by the State of Lower Saxony under the project "Qualität Plus" (ID: 27-73724/15-4). We would like to thank for their support. 


\section{References}

1. Schaffer, N., Pfaff, M., Kcrmar, H.: Dynamic Business Models: A Comprehensive Classification of Literature. In: MCIS 2019 Proceedings, 13 (2019)

2. Bouwman, H., de Reuver, M., Heikkilä, M., Fielt, E.: Business model tooling: where research and practice meet. Electronic Markets 30, 413-419 (2020)

3. Täuscher, K., Abdelkafi, N.: Visual tools for business model innovation: Recommendations from a cognitive perspective. Creativity and Innovation Management 26, 160-174 (2017)

4. Osterwalder, A., Pigneur, Y.: Business model generation: a handbook for visionaries, game changers, and challengers. John Wiley \& Sons, Hoboken (2010)

5. Amit, R., Zott, C.: Creating Value Through Business Model Innovation. MIT Sloan Management Review 53, 36-44 (2012)

6. Forrester, J.W.: Industrial Dynamics. MIT Press, Cambridge, USA (1961)

7. Moellers, T., von der Burg, L., Bansemir, B., Pretzl, M., Gassmann, O.: System dynamics for corporate business model innovation. Electronic Markets 29, 387-406 (2019)

8. John, T., Kundisch, D., Szopinski, D.: Visual Languages for Modeling Business Models: A Critical Review and Future Research Directions. In: ICIS 2017 Proceedings, 17 (2017)

9. Groesser, S.N., Jovy, N.: Business model analysis using computational modeling: a strategy tool for exploration and decision-making. Journal of Management Control 27, 61-88 (2016)

10. Abdelkafi, N., Täuscher, K.: Business Models for Sustainability From a System Dynamics Perspective. Organization \& Environment 29, 74-96 (2016)

11. Cosenz, F., Noto, G.: A dynamic business modelling approach to design and experiment new business venture strategies. Long Range Planning 51, 127-140 (2018)

12. Köpp, S., Schwaninger, M.: Scrutinizing the Sustainability of Business Models: System Dynamics for Robust Strategies. University of St. Gallen, St. Gallen, Switzerland (2014)

13. Cosenz, F., Rodrigues, V.P., Rosati, F.: Dynamic business modeling for sustainability: Exploring a system dynamics perspective to develop sustainable business models. Business Strategy and the Environment 29, 651-664 (2020)

14. Cosenz, F.: Supporting start-up business model design through system dynamics modelling. Management Decision 55, 57-80 (2017)

15. Featherston, C.R., Doolan, M.: A Critical Review of the Criticisms of System Dynamics. In: 30th International Conference of the System Dynamics Society (2012)

16. Hevner, A.R., Ram, S., March, S.T.: Design Science in Information Systems Research. Management Information Systems Quarterly 28, 75-105 (2004)

17. Vaishnavi, V., Kuechler, B. and Petter, S.: Design Science Research in Information Systems, http://desrist.org/design-research-in-information-systems/ (Accessed: 26.11.2020)

18. Frakes, W.B., Kang, K.: Software Reuse Research: Status and Future. IEEE Transactions on Software Engineering 31, 529-536 (2005)

19. Fettke, P., Loos, P.: Referenzmodellierungsforschung. Wirtschaftsinformatik 46, 331-340 (2004)

20. vom Brocke, J.: Referenzmodellierung. Gestaltung und Verteilung von Konstruktionsprozessen. Logos-Verlag, Berlin (2015)

21. Becker, J., Delfmann, P., Knackstedt, R.: Adaptive reference modeling: Integrating configurative and generic adaptation techniques for information models. In: Becker, J., Delfmann, P. (eds.) Reference Modeling, pp. 27-58. Physica-Verlag, Heidelberg, Germany (2007)

22. Becker, J., Knackstedt, R., Pfeiffer, D., Janiesch, C.: Configurative method engineering - on the applicability of reference modeling mechanisms in method engineering. In: AMCIS 2007 Proceedings (2007) 
23. Fettke, P., Loos, P.: Classification of reference models: a methodology and its application. Information Systems and e-Business Management 1, 35-53 (2003)

24. Scheer, A.-W., Nüttgens, M.: ARIS architecture and reference models for business process management. In: van der Aalst, W., Desel, J., Oberweis, A. (eds.) Business Process Management, pp. 376-389. Springer-Verlag Berlin Heidelberg, Berlin, Heidelberg, Germany (2000)

25. Scheer, A.-W.: Business Process Engineering: Reference Models for Industrial Enterprises. Springer-Verlag Berlin Heidelberg, Berlin, Heidelberg, Germany (1998)

26. Fellmann, M., Koschmider, A., Laue, R., Schoknecht, A., Vetter, A.: Business process model patterns: state-of-the-art, research classification and taxonomy. Business Process Management Journal 25, 972-994 (2019)

27. Legner, C., Pentek, T., Otto, B.: Accumulating Design Knowledge with Reference Models: Insights from 12 Years' Research into Data Management. Journal of the Association for Information Systems 21, 735-770 (2020)

28. Keller, R., König, C.: A reference model to support risk identification in cloud networks. In: Proceedings of the 35th International Conference on Information Systems (2014)

29. Han, E., Suh, B., Shin, S.K.: Developing a Reference Model for Analyzing Mobile Platform Business: From an Ecosystem View. In: AMCIS 2016 Proceedings (2016)

30. Gilsing, R.A.M., Türetken, O., Grefen, P. W. P. J., Adali, O.E.: A reference model for the design of Service-Dominant Business Models in the smart mobility domain. In: Proceedings of the 39th International Conference on Information Systems (2018)

31. Schmid, B.F., Lindemann, M.A.: Elements of a reference model for electronic markets. In: Proceedings of the Thirty-First Hawaii International Conference on System Sciences, pp. 193-201 (1998)

32. Pundoor, G., Herrmann, J.W.: A hierarchical approach to supply chain simulation modelling using the Supply Chain Operations Reference model. International Journal of Simulation and Process Modelling 2, 124-132 (2006)

33. Bagheri, E., Ghorbani, A.A.: UML-CI: A reference model for profiling critical infrastructure systems. Information Systems Frontiers 12, 115-139 (2010)

34. Xu, L., Tan, W., Zhen, H., Shen, W.: An approach to enterprise process dynamic modeling supporting enterprise process evolution. Information Systems Frontiers 10, 611-624 (2008)

35. Cosenz, F., Noto, G.: Fostering entrepreneurial learning processes through Dynamic Startup business model simulators. The International Journal of Management Education 16, 468$482(2018)$

36. Cosenz, F., Bivona, E.: Fostering growth patterns of SMEs through business model innovation. A tailored dynamic business modelling approach. Journal of Business Research (2020, In Press)

37. Gomez Segura, M., Oleghe, O., Salonitis, K.: Analysis of lean manufacturing strategy using system dynamics modelling of a business model. International Journal of Lean Six Sigma (2019, Ahead of Print)

38. Bianchi, C.: Introducing SD modelling into planning and control systems to manage SMEs' growth: a learning-oriented perspective. System Dynamics Review 18, 315-338 (2002)

39. Matook, S., Indulska, M.: Improving the quality of process reference models: A quality function deployment-based approach. Decision Support Systems 47, 60-71 (2009)

40. Rosemann, M., van der Aalst, W.: A configurable reference modelling language. Information Systems 32, 1-23 (2007)

41. vom Brocke, J.: Design Principles for Reference Modeling: Reusing Information Models by Means of Aggregation, Specialisation, Instantiation, and Analogy. In: Fettke, P., Loos, P. (eds.) Reference Modeling for Business Systems Analysis, pp. 47-76. IGI Global (2007) 
42. Simantics: Simantics System Dynamics: Open Source modelling and simulation tool for Simantics, http://sysdyn.simantics.org/

43. vom Brocke, J., Simons, A., Niehaves, B., Reimer, K., Plattfaut, R., Cleven, A.: RECONSTRUCTING THE GIANT: ON THE IMPORTANCE OF RIGOUR IN DOCUMENTING THE LITERATURE SEARCH PROCESS. In: ECIS 2009 Proceedings (2009)

44. Wirtz, B.W., Pistoia, A., Ullrich, S., Göttel, V.: Business Models: Origin, Development and Future Research Perspectives. Long Range Planning 49, 36-54 (2016)

45. Auer, C., Follack, M.: Using Action Research for Gaining Competitive Advantage out of the Internet's Impact on Existing Business Models. BLED 2002 Proceedings (2002)

46. Bivona, E., Montemaggiore, G.B.: Understanding short- and long-term implications of "myopic" fleet maintenance policies: a system dynamics application to a city bus company. System Dynamics Review 26, 195-215 (2010)

47. Currie, W.L., Joyce, P., Winch, G.: Evaluating Application Service Provisioning Using System Dynamics Methodology. British Journal of Management 18, 172-191 (2007)

48. Fang, Y., Davidsen, P.: Building Business-to-Consumer Competence in Chinese FastGrowing Industries: A System Dynamics Model. In: AMCIS 2003 Proceedings, 133 (2003)

49. Mayo, D.D., Dalton, W.J., Callaghan, M.J.: Steering strategic decisions at London underground: evaluating management options with system dynamics. In: Proceedings of the 2003 International Conference on Machine Learning and Cybernetics, pp. 1578-1584. IEEE (2003)

50. Risch, J.D., Troyano-Bermúdez, L., Sterman, J.D.: Designing corporate strategy with system dynamics: a case study in the pulp and paper industry. System Dynamics Review 11, 249274 (1995)

51. Strohhecker, J., Größler, A.: Implementing Sustainable Business Strategies. System Research and Behavioral Science 29, 547-570 (2012)

52. Hajiheydari, N., Zarei, B.: Developing and manipulating business models applying system dynamics approach. Journal of Modelling in Management 8, 155-170 (2013)

53. vom Brocke, J., Buddendieck, C.: Konstruktionstechniken für die Referenzmodellierung Systematisierung, Sprachgestaltung und Werkzeugunterstützung. In: Becker, J., Delfmann, P. (eds.) Referenzmodellierung, pp. 19-49. Physica-Verlag, Heidelberg (2004)

54. Schoormann, T., Behrens, D., Knackstedt, R.: The Noblest Way to Learn Wisdom is by Reflection: Designing Software Tools for Reflecting Sustainability in Business Models. In: ICIS 2018 Proceedings (2018)

55. Szopinski, D., Schoormann, T., John, T., Knackstedt, R., Kundisch, D.: Software tools for business model innovation: current state and future challenges. Electronic Markets 30, 469494 (2019)

56. Osterwalder, A., Pigneur, Y.: Designing Business Models and Similar Strategic Objects: The Contribution of IS. Journal of the Association for Information Systems 14 (2013) 